years. The parents said he had been sick three days with high fever, intense headache and irritability. He had had initial convulsions. I found a temperature of $105^{\circ}$, moderate opisthotonos and rigidity of the neck extreme; he objected to any noise or light in the room and to being handled. The next day he had the cephalic cry and internal strabismus; he also had stiffness of lower extremities and tache cerebral. I saw him four days during which time the temperature remained $103^{\circ}$ to $105^{\circ}$. I then persuaded them to allow the boy to be sent to the hospital as they would not permit lumbar puncture at home.

On the evening of Feb. 10, with a temperature of $103^{\circ}, 20 \mathrm{ccm}$. of Flexner's antiserum was injected by Dr. E. L. Hunt, Asst. Pathologist at Worcester City Hospital. The white count was 18,400 . On the morning of Feb. 11, temperature was $105^{\circ}$. At noon another $20 \mathrm{ccm}$. were injected; temperature in afternoon was $104.5^{\circ}$. On the morning of Feb. 12, temperature dropped to $98.5^{\circ}$ and all symptoms except slight irritability disappeared. White count 9,000. Conr valescence uninterrupted since that time.

Dr. Wentworth called attention to a paper on the serum treatment of cerebrospinal meningitis by Levy which appeared in a January number of the Deutsche Medizinische Wochenschrift. The "Kolle-Wassermann" serum was used. In this paper Levy gives the results of treatment of 55 cases of cerebrospinal meningitis which occurred in the town of Essen from January to November, 1907. Of these 55 cases, 15 were treated outside of the hospital without serum and showed a mortality of $80 \% ; 14$ cases were treated in the hospital without serum and showed a mortality of $78+\%$; in 17 cases the "Kolle-Wassermann" serum was injected intra-spinally and the mortality was $11+\%$. Levy lays stress on the value of early treatment with serum and the necessity for its intra-spinal injection to obtain good results.

\section{THE USE OF FAT-FREE MILK IN INFANT FEEDING.*}

BY CHARLES W. TOWNSEND, M.D., Boston.

ANY suggestion which simplifies infant feeding or renders the management of cases of indigestion and diarrhea in infancy easier, is certainly worthy of consideration, for it is a noteworthy fact that the general practitioner is prone to shirk the careful study which a thorough conception of scientific percentage feeding entails.

For a long time the proteids of cow's milk have absorbed much of the attention of specialists in infant feeding, and it has been thought that once these proteids were thoroughly understood and modified to resemble the proteids of mother's milk, the problem of infant feeding would be largely solved.

Curds in infant stools are generally regarded as evidence of faulty proteid digestion,for it is thought that the cheesy part of the milk, instead of being digested, is curdled and passed through the gastrointestinal tract. Whenever these curds occur, efforts are made to modify the proteids which are considered to blame. In working out this problem, whey, which lacks the caseinogen so largely in excess in cow's milk, has been used, as well as

* Read before the Suffolk District Medical Society, Dec. 18, 1907. the apparently more scientific but more complicated split proteids, where the same relative proportions of soluble lactalbumen and the caseinogen may be prescribed as in woman's milk.

While the proteids have been studied so carefully, the fat in the mixtures for infant feeding has, on the other hand, often received but scant attention. This, I believe, is due to the fact that the fat of cow's milk and of woman's milk both occur in about the same proportion to the total bulk, and no differences in the quality of the ingredients are recognized by the practitioner as is done in the case of the proteids. The quantity of the fat is borne in mind, but the quality is not considered, yet it has been shown, as by Stern," "that the composition of the fat of cow's milk is greatly at variance with that of the fat of human milk, differing especially in its far greater contents of volatile fatty acids, among which butyric acid is the most important." He finds from six to eight times as much of these fatty acids as in normal woman's milk, a fact that easily explains some, at least, of the relative indigestibility of cow's milk.

Another interesting fact is the one discovered by Luzzatti and Biolchini, namely, that there is a more active fat-splitting ferment in woman's milk than in cow's milk.

Although the value of fat as a food is generally recognized by the practitioner, it is often regarded by him more in the light of a laxative, and, if the bowels are constipated, he is apt to increase the percentage of this ingredient without hesitation. That excess of fat is often a cause of constipation is rarely recognized. Such, however, is the case, and stools are passed that are hard, dry, large, and of a grayish white color, showing a greasy surface when rubbed smooth. In these stools there may or may not be found hard curdy masses like cheese which are often thought to be made up of proteids, but are in reality masses of fat. A diminution in the amount of fat in the food in these cases will often relieve the constipation, much to the surprise of the physician, whose only idea previously had been to increase the fat for its laxative action. Too little fat, it must be borne in mind, will also cause constipation, so that a happy mean for each case is desirable.

Excess of fat is often a cause of gastric disturbance as shown by vomiting, and of intestinal indigestion resulting in the fatty stools just described, and in a failure to gain properly in weight. The infant may even become atrophic. Infants fed with an excess of fat are often ravenous at their meals, - they are starving in the midst of plenty, -and the physician is tempted to increase the strength of the food, especially in fat, with increased trouble for the little patient. Grave general disturbances, as shown by eczema, rachitis, or even convulsions, may occur in infants thus overfed. It must always be borne in mind, however, that what is a proper amount of fat in the food in one case may be excessive and the cause of considerable disturbance in another. No cast-iron rule can be made for infant feeding.

\footnotetext{
1 Archives of Pediatrics, June, 1905.
} 
The quality of the fat of Jersey and Guernsey milk, aside from its quantity, is in some infants often a cause of digestive disturbance. I have many times seen babies gain but slowly and show fatty stools on Jersey milk modifications, even when the percentage of fat was low, while the same babies gained rapidly and digested well the modifications having the same amount of fat, made with the milk of Ayrshire, Holstein or common red cows. Another cause for the difficult digestion of fat is sometimes seen where centrifugal cream is used, and a simple change to gravity cream often obviates the difficulty.

While we must all admit that fat in the normal infant's food is a very desirable and a very necessary ingredient, another problem presents itself when the infant's gastro-intestinal tract is disturbed, and unable to properly dispose of the food. Here our object is to feed the infant in such a way that the stomach and bowel disturbance will subside as quickly as possible, so that the infant can digest a proper amount of food. A simple and satisfactory treatment is the substitution of barley water for milk, followed by the gradual resumption of this important fluid. In this resumption the proteids, especially, are at first given cautiously in small amounts, often in the form of whey or as split proteids, for the proteids are generally believed to be the most difficult part of the milk to digest,- - the chief offenders, as it were. A number of recent writers have, however, come to the conclusion that the fats and not the proteids are the chief offenders, as I have already hinted, and Walls ${ }^{2}$ in a recent paper goes so far as to make the following statements:

"There is no evidence that the proteid of cow's milk causes any digestive disturbance in the infant"; and "all experiments prove that cow's proteid is easy to digest and resists putrefaction."

Such extreme views are little short of revolutionary. In order to test them, however, I fed, with but few exceptions, all the babies suffering from gastro-intestinal troubles, in my recent service in the Boston Floating Hospital, on fat-free milk. I am greatly indebted to Dr. W. P. Lucas, my senior house officer, for his careful study and analysis of these cases. My service began early in August, and I found the wards, containing fifty beds, full of infants fed on various modifications of milk, milk and barley water, split proteids, buttermilk and condensed milk. The diet of these was changed more or less gradually to fat-free milk and barley water. New cases, entering with the usual symptoms of diarrhea with curdy and mucous stools, with or without vomiting, and with or without a septic temperature, were given calomel or castor oil to clear them out, and were put on barley water and fat-free milk. In about one third of the cases the proportion of fat-free milk to barley water was one in ten at the outset, and the strength was increased daily. The remaining two thirds of the cases were begun at once on equal parts of barley water and fat-free milk, or on fat-

2 "The Digestion of the Proteids of Cow's Milk in Infancy." Frank X. Walls, M.D. Jour. Am. Med. Asso., April 27, 1907, p.
1389. free milk alone without any diluent. Eighty-five cases in all were treated.

Much to my surprise I found that undiluted fatfree milk, that is to say, milk containing $4 \%$ of proteids and $4 \%$ of sugar, but practically no fat, was well digested even by very young infants, so that during the latter part of my service, instead of cautiously giving them much diluted fat-free milk, I began at once on whole fat-free milk. For example, James P., four weeks old, weighing $6 \mathrm{lb}$. 10 oz., entered the hospital Aug. 29. He had not been thriving on various milk mixtures, and for two days had had foul smelling, green and watery movements, and had vomited after every feeding. To put such an infant on $4 \%$ of proteids would seem to be most unwise, yet he was given nothing during his fifteen days of stay but undiluted fat-free milk, and he did well. He stopped vomiting at once, took the fat-free milk eagerly, his stools became normal fat-free milk stools, and he gained weight, a total of $13 \mathrm{oz}$. during his fifteen days in the hospital.

Another striking case, which, like the one just described, would seem to show that even young infants can easily digest the $4 \%$ proteids of cow's milk, provided they are not burdened with the fats, is that of a fourteen weeks' breast-fed infant. This child had had diarrhea for five weeks, and had vomited frequently. No improvement had occurred while he was under treatment as a day patient, and was taking the harbor trips. Admitted to the wards he was at once put on undiluted fat-free milk. The vomiting ceased and the character of the stools changed from green, curdy and slimy to the normal fat-free milk stools.

The appearance of the stools in infants fed on fat-free milk is very characteristic and easily recognized. The stools are yellowish brown. They lack the bright yellow color of normal milk stools, and the white color of stools in which there is an excess of fat. They have almost an opalescent appearance. Their consistency is their most striking feature, as it is smooth and salve-like, and free from lumps or curds. In other words the curds one would expect to find from the excess of proteids are conspicuous by their absence. The odor of these stools is very slight, certainly not offensive.

One day numerous small curds appearedrin the stools of the infants fed on fat-free milk, and the infants all did badly. Under the microscope the white masses were found to be made up chiefly of bacteria, and on investigation it was discovered that the fat-free milk contained over a million bacteria per cubic centimeter. When the milk was sterilized the trouble ceased.

That fat-free milk appears to be as a rule bland and unirritating, even when a high temperature denotes septic absorption, the following cases show:

Gertrude W., six months old, entered on Sept. 5 with the history of diarrhea, vomiting, fretfulness and lack of appetite for five weeks. Dejections seven a day, green and watery. She was given castor oil and put at once on undiluted fatfree milk, notwithstanding the fever and gastro- 
intestinal symptoms. Her septic condition was shown by an irregular fever ranging from $99^{\circ}$ to $103^{\circ}$. The temperature reached normal on the eighth day, and the following note was made by Dr. Lucas: "Is doing very well in every way; movements are improving slowly and the appetite is fairly good."

George M., seven months old, had had green, slimy or curdy stools for two weeks, and had been feverish. The child was given castor oil and put on undiluted fat-free milk. The stools became yellow and salve-like on the fourth day, but the temperature did not reach normal until the ninth day. There was, however, a complicating bronchitis.

The probable explanation for the curds that were found in the stools of these infants while they were taking a food containing fat, and their absence when they were taking a food free from fat, although high in proteids, seems to be that the curds are due to fat and not to proteids.

Milk that is practically fat-free can be obtained only by the centrifugal process. This contains less than one half of $1 \%$ of fat. In private practice, where this is not so easily procured, I have used with satisfaction milk from which all the cream was removed by mean of the Chapin dipper or by the siphon. This milk, however, contains $1 \%$ or more of fat, and is to that extent liable to occasion trouble in a susceptible case. In mild cases of gastro-intestinal disturbance I have found that a moderate diminution in the amount of fat is often all that is necessary. This can be obtained by using whole milk instead of cream in the mixture, or by using milk from which the top few ounces have been poured off.

The ease with which the proteids appear to be digested by even young infants is certainly interesting and suggestive.

An infant fed on too low proteids is at a disadvantage, as shown by anemia, slowness in gaining weight, fretfulness, a tendency to intestinal indigestion and to infection. Yet many infants are condemned to their low proteid diet on account of the difficulty they have of digesting, not the proteids, but the fats that go with them. The use of dilutions or modifications of weak creams instead of the strong creams, so commonly advised, and the earlier recourse to undiluted cow's milk would, in the light of these studies, appear to be a more rational procedure.

Exact imitation of the percentages in woman's milk is far from being the solution of infant feeding. We must take heed lest we worship the fetish of percentage feeding too blindly, for, no matter how cleverly we calculate the fractions, or how nicely we split the proteids, the resulting mixture is still cow's milk and not woman's milk.

In conclusion, as a result of these preliminary studies, it may be said:

1. That while fat is very necessary to the normal infant, it is more often given in excess than is generally supposed.

2. Excess of fat may cause one or more of a number of symptoms, as, for example, constipation, white and "curdy" stools, a ravenous appetite with atrophy, convulsions.
3. In gastro-intestinal disturbances it is desirable to exclude fat.

4. The proteids of undiluted fat-free milk appear to be remarkably well borne even by young infants, and there is an absence of so-called curds from the stools.

\section{THE USE OF THE ROENTGEN RAY IN THE STUDY OF DISEASES IN CHILDREN.*}

BY ARIAL W. GEORGE, M.D., Boston.

IT is impossible in the few minutes given me to speak on this subject, to more than mention one or two points that may be of interest to you. Those of us who practice near the centers of medical work, where the laboratories are at hand, where the hospitals offer large clinics, and where the methods that are so practicable for us may not be available to others, can, perhaps, best appreciate the value of the Rontgen method.

The criticism has been made that the Rœntgen ray is a laboratory method, and is not accessible for the use of the general practitioner; therefore, in the few conditions that I shall mention or show this evening, I have eliminated all of those that are not of practical importance for early diagnosis, prognosis and treatment. I do not intend, in talking about the uses of the Rœntgen method, particularly to general practitioners or perhaps to those who are mostly interested in the study of children, to confine myself strictly to their medical aspect. It has always been apparent to me that, while, on the one hand, the medical side of disease in children has been elaborately studied from every point of view, on the other hand, the surgical side has been much neglected except where such disease relating to orthopedics is concerned. This is also especially noticeable when we compare the carefully studied diseases of adults with those of children.

The severe criticism made of the Rœntgen ray is that the picture produced by the use of a Rœntgenographic plate is nothing more nor less than a shadow, or shadows. The Rœntgenogram is a record of densities of the different parts under examination, recorded on the Rœntgenographic plate according to the laws of projection. A true Rœntgenogram of any part of the body is ideal if it shows on the plate the densities and resulting radiabilities that exist between tissues and bones, according to their atomic weights. A thorough knowledge of the normal living anatomy is absolutely necessary, as are all its variations. It is upon this one point, namely, thorough knowledge of the normal living anatomy of children, from birth to puberty, that rests the whole subject of the study of diseases in children by the Rœentgen method. It is not that we are attempting to say that by the Rœntgenr ay we can show pulmonary tuberculosis, or that we can demonstrate periosteal sarcoma absolutely; but that we do attempt, by synthesis, rather than by analysis, to determine just how the different tissues vary from the normal:

* Read at the meeting of the New England Pediatric Society Feb. 15, 1908 . 